\title{
Entry level caseload expectations and perception of full caseload capability during student physical therapist terminal clinical experiences: A pilot study
}

\author{
Erica Sherman*, Karen Berg and Susan Ann Talley \\ Department of Physical Therapy, College of Health Sciences, University of Michigan, Flint, Flint, MI, USA
}

\section{Abstract}

Purpose: The purpose of this study was to explore expected student physical therapist (PT) full caseload expectations across and within clinical settings and identify factors Clinical Instructor's (CI) routinely report as contributing to their assessment of a student's ability to manage a full caseload.

Methods: A cross-sectional electronic survey design was used to collect data from CIs for student PTs in Michigan. A sample of convenience was utilized.

Results: CIs $(\mathrm{n}=128)$ from six settings participated in this study. Respondents reported $32 \%$ of their employers had established caseload expectations for new graduate and student PTs. Within an 8-hour day, CIs considered a full student caseload measured in billable units to be 26 in outpatient ortho, 22.5 in outpatient neuro, 29 in outpatient mixed, 17.5 in paediatric, 18.5 in acute care, and 21.9 in inpatient rehab settings. Within an 8-hour day, CIs considered a full student caseload measured in patients per day to be 8.8 in outpatient ortho, 6.9 in outpatient neuro, 8.5 in outpatient mixed, 5.4 in paediatric, 7.1 in acute care, and 4.5 in inpatient rehab settings. Student capability was considered by $80 \%$ of CIs when determining student caseload. CIs reported patient complexity and accuracy of clinical reasoning as the most influential in determining a student's capability to manage a full caseload. The ability to implement and retain feedback was reported as least influential.

Conclusion: Most respondents indicated their site lacked defined and differing expectations for student PTs. The CIs consistently reported considering student capability of carrying a full caseload when making determinations of student performance on the CPI and were most influenced by patient complexity and clinical reasoning accuracy. CIs reported a range of full caseload productivity expectations for students both within and across settings, which may contribute to inconsistent assessment of student performance on the CPI.

Keywords: student physical therapist; caseload; assessment

A s entry level Doctor of Physical Therapy programmes look to prepare graduates ready to enter clinical physical therapist practice, ${ }^{1}$ it is important that the assessment tool used to evaluate student physical therapists' ('students') clinical performance be objective and reflect the realities of the clinical environment.
Within the Consensus Statement on Clinical Judgement in Health Care Settings, the American Physical Therapy Association (APTA) identifies patient-centred outcomes as the true measure of quality care for patients ${ }^{2}$ and discourages unethical productivity quotas., ${ }^{2,3}$ But the reality of clinical practice is that productivity measures permeate

A poster presentation of this work was presented at APTA Educational Leadership Conference 2019 
the profession. A study by Tammany et al. ${ }^{4}$ reported over $70 \%$ of respondents worked in settings where employers had productivity expectations.

The most widely used tool for assessing student performance is the Clinical Performance Instrument: Version 2006 (CPI). ${ }^{5}$ Each of the 18 performance criteria within the CPI use a performance scale consisting of six anchor ratings ranging from beginner to beyond entry-level performance, with delineated performance dimensions for supervision/guidance, quality, complexity, consistency, and efficiency. ${ }^{6}$ The CPI has good validity and internal consistency $($ Cronbach alpha $=0.99) .{ }^{7}$

Three CPI anchor scale definitions specify the percentage of a full-time physical therapist caseload a student is capable of managing, ranging from $50 \%$ at intermediate performance to $100 \%$ at entry level performance (ELP). The CPI instructions do not indicate a quantitative expectation of a full caseload to use when determining the percentage, but instead prompts the clinical instructor's (CI) to report caseload expectations at the clinical site for a new graduate and 'considering the anchor ratings, what percentage of a new graduate caseload is the student $\mathrm{ca}$ pable of managing, ${ }^{6}$ implying the employer's expectation is the full caseload benchmark. Whilst a range in performance expectations across settings may be necessary because of the differing patient needs, a range in employer expectations within settings may influence the CI's expectations of student caseload and the subsequent student performance rating on the CPI, making student ratings less consistent.

The CPI also allows for CIs to rate student performance using perceived caseload capability instead of actual caseload managed. ${ }^{6}$ Concerns regarding variability in caseload interpretation, ${ }^{8}$ subjectivity, ${ }^{9-13}$ and inconsistency between narrative comments and performance ratings ${ }^{14,15}$ within the CPI have been documented. Variability in caseload is problematic because these ratings and comments are the most common objective source of information for Directors of Clinical Education (DCE) about a student's performance. ${ }^{16}$

The CPI incorporates caseload as a performance modifier across all 18 criteria. ${ }^{6}$ Variability in employer productivity expectations may contribute to variability in a CI's expectation for student caseload, making it difficult to determine if a student has met the expected ELP requirement for a clinical experience. For this study, 'caseload' is used when discussing the CI's expectations of a student's performance and 'productivity' is used when discussing the employer's expectations of an employed physical therapist. The purpose of this study was to explore expected student caseloads across and within clinical settings and identify factors CIs routinely report as contributing to their assessment of a student's ability to manage a full caseload.

\section{Methods}

Design

A cross-sectional survey design was used to collect data from CIs evaluating student physical therapists in Michigan. The study was exempt for review by the university Institutional Review Board (HUM134148). Participants provided informed consent when they opened the survey.

\section{Sample}

This study used a sample of convenience. An electronic survey link was distributed to current Site Coordinators of Clinical Education (SCCE) and CIs $(n=1,196)$ for the entry-level physical therapist education programme. The SCCE was asked to disseminate the link to staff physical therapists at their facility. A postcard with an electronic survey link was mailed to all physical therapists on the Michigan Physical Therapy Association membership list who were not current SCCE or CIs for the university ( $n=$ 1,818). Lists were cross-referenced to prevent duplication. Survey design prevented duplication by not accepting more than one survey from the same IP address. A survey reminder was provided one month later. Inclusion criteria limited the sample to CI's for student physical therapists at a site located in Michigan.

\section{Survey development}

The survey was developed by two DCE and the associate director for professional education, all APTA Advanced Credentialed Clinical Instructor. Survey items were developed by one DCE, reviewed by the other team members, and revised until consensus was reached. The survey was reviewed by two external experts for clarity, organisation and content, with revisions made from feedback. The survey consisted of 25 items, including 13 demographic items and 12 items about determining a full caseload within the CPI (Appendix 1). Productivity and caseload were defined as the number of patients seen and the number of units billed per 8-hour workday. Participants were asked to rank eight factors that they considered when determining a student's capability to maintain a full caseload $(1=$ most influential, $8=$ least influential). Factors included as influential in CI's perception of capability were based on previous published findings. ${ }^{11,17}$ A Qualtrics (Qualtrics, Provo, UT) survey software was used to distribute the survey.

\section{Data analysis}

Data was analysed using Statistical Package for Social Sciences Statistics (SPSS) 24. ${ }^{18}$ Descriptive statistics were computed for demographic and study variables. Median and range were computed for variables with a non-normal distribution. Crosstab/Pearson correlations were computed to analyse the distribution of demographic 
variables across settings. Parametric (analysis of variance) with appropriate corrections (Welch's F, Tukey) as well as non-parametric (e.g. Spearman rho, Kruskall Wallace) analyses were used when assumptions were not

Table 1. Participant demographic characteristics for full sample

\begin{tabular}{lc}
\hline Characteristic & Total \\
\hline Participants & 128 \\
$n(\%)$ & $(100 \%)$ \\
Age (years) & 37 \\
median (range) & $(26-66)$ \\
Female & 96 \\
$n$ (\%) & $(75 \%)$ \\
Years as physical therapist & $1 \mathrm{I}$ \\
median (range) & $(1-44)$ \\
Years as clinical instructor & 6 \\
median (range) & $(I-40)$ \\
Years at current site & 6 \\
median (range) & $(I-38)$ \\
Clinical instructor for number of full time students past & 2 \\
2 years & $(0-8)$ \\
median (range) & \\
APTA Credentialed Basic Clinical Instructor & 80 \\
$n$ (\%) & $62.5 \%$ \\
Number of physical therapists at current site & 8 \\
median (range) & $(I-300)$ \\
Number of students/year at current site & 3 \\
median (range) & $(0-55)$ \\
\hline &
\end{tabular}

met. Participants ranked factors they considered when determining a student's capability to maintain a full caseload $(1=$ most influential, $8=$ least influential $)$. Median rank scores and the number and percentage of individuals ranking a factor as most and least influential were calculated.

\section{Results}

\section{Participants}

Of the 201 individuals who opened the study link, 128 (median age $=39.8[26-66]$ years, $75 \%$ female) met the inclusion criteria. The majority $(n=110,89.4 \%)$ of the 128 reported completing the CPI training online. One-third $(33.6 \%)$ practiced in an outpatient (OP) orthopaedic setting. Table 1 presents the demographic characteristics for the full sample. Because of the similarity of some patient population settings, the initial 13 settings included in the survey were collapsed into 6 distinct settings for analysis. For example, inpatient acute care-non-critical care and inpatient acute care-critical care settings were collapsed into a single setting called acute care. Table 2 shows the demographic characteristics across settings. Analysis showed no statistically significant differences across settings for age, gender, years as a physical therapist, years as a CI, or being a credentialed APTA CI. There was a statistically significant difference in years employed at the

Table 2. Participant demographic characteristics by setting

\begin{tabular}{|c|c|c|c|c|c|c|}
\hline \multirow[t]{2}{*}{ Characteristic } & \multicolumn{6}{|c|}{ Setting } \\
\hline & OP ortho & Acute care & Paediatrics & IPR & OP neuro & OP mixed \\
\hline $\begin{array}{l}\text { Participants } \\
n(\%)\end{array}$ & $\begin{array}{c}43 \\
(33.6 \%)\end{array}$ & $\begin{array}{c}37 \\
(28.9 \%)\end{array}$ & $\begin{array}{c}13 \\
(10.2 \%)\end{array}$ & $\begin{array}{c}9 \\
(7.0 \%)\end{array}$ & $\begin{array}{c}8 \\
(6.3 \%)\end{array}$ & $\begin{array}{c}7 \\
(5.5 \%)\end{array}$ \\
\hline $\begin{array}{l}\text { Age (years) } \\
\text { median (range) }\end{array}$ & $\begin{array}{c}42 \\
(28-64)\end{array}$ & $\begin{array}{c}35 \\
(27-64)\end{array}$ & $\begin{array}{c}35 \\
(29-66)\end{array}$ & $\begin{array}{c}37 \\
(3 \mid-57)\end{array}$ & $\begin{array}{c}49 \\
(27-63)\end{array}$ & $\begin{array}{c}42 \\
(3 \mid-54)\end{array}$ \\
\hline $\begin{array}{l}\text { Female } \\
n(\%)\end{array}$ & $\begin{array}{c}27 \\
(62.8 \%)\end{array}$ & $\begin{array}{c}30 \\
(81.1 \%)\end{array}$ & $\begin{array}{c}12 \\
(92.3 \%)\end{array}$ & $\begin{array}{c}8 \\
(88.9 \%)\end{array}$ & $\begin{array}{c}6 \\
(75.0 \%)\end{array}$ & $\begin{array}{c}4 \\
(57.1 \%)\end{array}$ \\
\hline $\begin{array}{l}\text { Years as physical therapist } \\
\text { median (range) }\end{array}$ & $\begin{array}{c}12 \\
(2-43)\end{array}$ & $\begin{array}{c}8 \\
(2-38)\end{array}$ & $\begin{array}{c}9 \\
(3-44)\end{array}$ & $\begin{array}{c}9 \\
(6-35)\end{array}$ & $\begin{array}{c}24 \\
(2-40)\end{array}$ & $\begin{array}{c}12 \\
(1-35)\end{array}$ \\
\hline $\begin{array}{l}\text { Years as clinical instructor } \\
\text { median (range) }\end{array}$ & $\begin{array}{c}7 \\
(I-35)\end{array}$ & $\begin{array}{c}5 \\
(I-30)\end{array}$ & $\begin{array}{c}4 \\
(I-40)\end{array}$ & $\begin{array}{c}4 \\
(2-25)\end{array}$ & $\begin{array}{l}14.5 \\
(I-36)\end{array}$ & $\begin{array}{c}7 \\
(I-20)\end{array}$ \\
\hline $\begin{array}{l}\text { Years at current site } \\
\text { median (range) }\end{array}$ & $\begin{array}{c}6.5 \\
(I-26)\end{array}$ & $\begin{array}{c}5 \\
(I-38)\end{array}$ & $\begin{array}{c}4 \\
(I-33)\end{array}$ & $\begin{array}{c}4.5 \\
(3-3 I)\end{array}$ & $\begin{array}{c}22.5 \\
(2-38)\end{array}$ & $\begin{array}{l}11 \\
(I-24)\end{array}$ \\
\hline $\begin{array}{l}\text { Number of full time students past } 2 \text { years } \\
\text { median (range) }\end{array}$ & $\begin{array}{c}2 \\
(0-7)\end{array}$ & $\begin{array}{c}2 \\
(0-8)\end{array}$ & $\begin{array}{c}2 \\
(I-4)\end{array}$ & $\begin{array}{c}2 \\
(0-5)\end{array}$ & $\begin{array}{c}1 \\
(0-8)\end{array}$ & $\begin{array}{c}2 \\
(0-4)\end{array}$ \\
\hline $\begin{array}{l}\text { APTA credentialed basic clinical instructor } \\
n(\%)\end{array}$ & $\begin{array}{c}23 \\
(53.5 \%)\end{array}$ & $\begin{array}{c}25 \\
(67.57 \%)\end{array}$ & $\begin{array}{c}5 \\
(38.5 \%)\end{array}$ & $\begin{array}{c}6 \\
(66.7 \%)\end{array}$ & $\begin{array}{c}6 \\
(75.0 \%)\end{array}$ & $\begin{array}{c}4 \\
(57.1 \%)\end{array}$ \\
\hline $\begin{array}{l}\text { Physical therapists' years at current site } \\
\text { median (range) }\end{array}$ & $\begin{array}{c}5 \\
(I-38)\end{array}$ & $\begin{array}{c}23.5 \\
(3-100)\end{array}$ & $\stackrel{9}{(1-20)}$ & $\begin{array}{c}6 \\
(4-100)\end{array}$ & $\begin{array}{c}12 \\
(1-75)\end{array}$ & $\begin{array}{c}5 \\
(2-300)\end{array}$ \\
\hline $\begin{array}{l}\text { Students/year at current site } \\
\text { median (range) }\end{array}$ & $\begin{array}{c}2 \\
(0-25)\end{array}$ & $\begin{array}{c}5.5 \\
(1-22)\end{array}$ & $\begin{array}{c}2.5 \\
(1-10)\end{array}$ & $\begin{array}{c}5 \\
(2-50)\end{array}$ & $\begin{array}{l}3.2 \\
(1-55)\end{array}$ & $\begin{array}{c}2 \\
(1-3)\end{array}$ \\
\hline
\end{tabular}

OP Ortho, Outpatient Orthopaedics; IPR, Inpatient Rehabilitation; OP Neuro, Outpatient Neurology; OP Mixed, Outpatient Mixed Caseload; APTA, American Physical Therapist Association. 
current site across settings $(F=2.647, d f 1=5, d f 2=111$, $P=0.027$ ) Mean years employed at the current site were statistically significantly longer for participants employed at OP neurology sites compared to OP orthopaedic $(P=$ $0.040)$, paediatric $(P=0.016)$, and acute care $(P=0.019)$ settings. There was a statistically significant difference in the number of physical therapists employed at the current site across settings $(F=5.227, d f 1=5, d f 2=22.481, P$ $=0.002)$, with acute care settings having more licensed physical therapists than did OP orthopaedic $(P=0.000)$ and paediatric settings $(P=0.001)$. In addition, there was a statistically significant difference in the number of full time student physical therapists per year across settings $(F$ $=6.290, d f 1=5, d f 2=27.505, P=0.000)$, with acute care sites having more full time student physical therapists per year than OP orthopaedic $(P=0.010)$ and OP mixed $(P$ $=0.000)$ settings.

\section{Caseload expectations}

Most participants defined employer productivity targets for licensed physical therapist for a full caseload both by the number of patients seen and billable units recorded per day $(n=63,50.4 \%)$, followed by billable units $(n=47$, $37.6 \%)$, and then number of patients seen $(n=15,11.7 \%)$.
The preferred method for determining productivity varied across settings $\left(\chi^{2}=30.878, d f=10, P=0.001\right)$ with the number of patients seen primarily reported in OP orthopaedic and mixed OP settings, whilst the use of billable units was more commonly used in paediatric, acute care, and inpatient rehabilitation settings. In all $32 \%(n=41)$ of participants indicated that their employer's productivity expectations were lower for student and new graduate physical therapists compared to those of experienced physical therapists. Lower productivity standards were reported consistently across settings $\left(\chi^{2}=8.77, d f=10\right.$, $P=0.554)$. In facilities where there were lower expectations for new graduates and students, $74 \%$ of the respondents reported that new graduates and students had the same performance expectations. Clinician productivity and student caseload targets for a full caseload are shown in Tables 3 and 4. The billable units data for students in OP orthopaedics and licensed physical therapists in paediatrics were skewed and kurtotic. The expected number of patients per day data was skewed for both physical therapists and students in OP neuro and acute care and licensed physical therapists in OP orthopaedics. This data was kurtotic for physical therapists and students in OP orthopaedics and neuro, but only licensed physical therapists in OP

Table 3. Number of billable units required for a full caseload by setting

\begin{tabular}{|c|c|c|c|c|c|c|c|c|c|c|c|c|}
\hline & \multicolumn{2}{|c|}{ Outpatient ortho } & \multicolumn{2}{|c|}{ Outpatient neuro } & \multicolumn{2}{|c|}{ Outpatient mixed } & \multicolumn{2}{|c|}{ Paediatric } & \multicolumn{2}{|c|}{ Acute } & \multicolumn{2}{|c|}{ Inpatient rehab } \\
\hline & $\mathrm{PT}^{*}$ & $\mathrm{SPT} * *$ & PT & SPT & PT & SPT & PT & SPT & PT & SPT & PT & SPT \\
\hline$N$ & 31 & 27 & 8 & 8 & 4 & 3 & 10 & 8 & 34 & 30 & 9 & 9 \\
\hline Mean & 32.7 & 26.9 & 26.3 & 22.5 & 27.1 & 29 & 20.0 & 17.5 & 20.8 & 18.5 & 23.4 & 21.9 \\
\hline SD**** & 12.9 & 9.7 & 2.5 & 3.5 & 19.4 & 13.9 & 5.2 & 2.2 & 4.4 & 4.1 & 2.5 & 2.7 \\
\hline $\begin{array}{l}\mathrm{Cl} 95 \% * * * * * \\
\text { lower }\end{array}$ & 27.9 & 23.0 & 24.2 & 19.6 & -3.8 & -5.5 & 16.3 & 15.7 & 19.2 & 16.9 & 21.5 & 19.8 \\
\hline upper & 37.4 & 30.8 & 28.3 & 25.4 & 58.1 & 63.5 & 23.7 & 19.3 & 22.3 & 19.9 & 25.4 & 23.9 \\
\hline Median & 28 & 25 & 28 & 24 & 31.8 & 22 & 20 & 16.7 & 22 & 18 & 24 & 21 \\
\hline Range (min-max) & $4-63$ & $15-56$ & $22-22$ & $18-28$ & $0-45$ & $20-45$ & $7-25$ & $15-20$ & $14-32$ & $1 \mid-24$ & $20-26$ & $18-26$ \\
\hline
\end{tabular}

*PT, Physical Therapist; **SPT, Student Physical Therapist; ***, Standard Deviation; **** Cl, Confidence Interval.

Table 4. Number of patients required for a full caseload by setting

\begin{tabular}{|c|c|c|c|c|c|c|c|c|c|c|c|c|}
\hline & \multicolumn{2}{|c|}{ Outpatient ortho } & \multicolumn{2}{|c|}{ Outpatient neuro } & \multicolumn{2}{|c|}{ Outpatient mixed } & \multicolumn{2}{|c|}{ Pediatric } & \multicolumn{2}{|c|}{ Acute } & \multicolumn{2}{|c|}{ Inpatient rehab } \\
\hline & $\mathrm{PT}^{*}$ & SPT*** & PT & SPT & PT & SPT & PT & SPT & PT & SPT & PT & SPT \\
\hline $\bar{N}$ & 38 & 32 & 8 & 7 & 6 & 4 & 12 & 9 & 33 & 33 & 7 & 8 \\
\hline Mean & 11.0 & 8.8 & 7.4 & 6.9 & 9.8 & 8.5 & 6.9 & 5.4 & 8.1 & 7.1 & 4.4 & 4.5 \\
\hline SD**** & 3.6 & 2.3 & 1.9 & 1.5 & 3.9 & 3.1 & 1.7 & 1.2 & 2.0 & 1.6 & 0.9 & 0.4 \\
\hline \multicolumn{13}{|c|}{$\mathrm{Cl} 95 \% * * * * *$} \\
\hline lower & 9.8 & 7.9 & 5.8 & 5.5 & 5.8 & 3.6 & 5.8 & 4.5 & 7.4 & 6.5 & 3.5 & 4.1 \\
\hline upper & 12.2 & 9.6 & 9.0 & 8.2 & 8.0 & 13.5 & 8.0 & 6.4 & 8.8 & 7.7 & 5.2 & 4.9 \\
\hline Median & 9 & 9 & 7 & 6 & 7.3 & 7.5 & 6.3 & 5 & 7 & 7 & 4 & 4.5 \\
\hline Range & $7-24$ & $5-16$ & $6-12$ & $6-10$ & $6-13$ & $6-13$ & $5-11$ & $4-8$ & $5-14$ & $5-11$ & $3-6$ & $4-5$ \\
\hline
\end{tabular}

*PT, Physical Therapist; **SPT, Student Physical Therapist; ***,Standard Deviation; **** Cl, Confidence Interval. 
Table 5. Ranked factors influencing determining student capacity to manage a full caseload $(n=105)$

\begin{tabular}{|c|c|c|c|}
\hline & $\begin{array}{l}\text { Median rank* } \\
\text { (Range) }\end{array}$ & $\begin{array}{c}\text { Most } \\
\text { influential } \\
\mathrm{n}(\%)\end{array}$ & $\begin{array}{c}\text { Least } \\
\text { influential } \\
\mathrm{n}(\%)\end{array}$ \\
\hline Patient complexity & $\begin{array}{c}3 \\
(1-8)\end{array}$ & $\begin{array}{c}36 \\
(33.6 \%)\end{array}$ & $\begin{array}{c}15 \\
(14.0 \%)\end{array}$ \\
\hline Clinical reasoning accuracy & $\begin{array}{c}3 \\
(1-8)\end{array}$ & $\begin{array}{c}22 \\
(20.6 \%)\end{array}$ & $\begin{array}{c}1 \\
(.5 \%)\end{array}$ \\
\hline Ability to multitask & $\begin{array}{c}4 \\
(1-8)\end{array}$ & $\begin{array}{c}18 \\
(16.8 \%)\end{array}$ & $\begin{array}{c}14 \\
(13.1 \%)\end{array}$ \\
\hline Clinical reasoning speed & $\begin{array}{c}4 \\
(2-8)\end{array}$ & $\begin{array}{c}16 \\
(15.0 \%)\end{array}$ & $\begin{array}{c}6 \\
(5.6 \%)\end{array}$ \\
\hline Documentation efficiency & $\begin{array}{c}5 \\
(1-8)\end{array}$ & $\begin{array}{c}13 \\
(12.1 \%)\end{array}$ & $\begin{array}{c}13 \\
(12.1 \%)\end{array}$ \\
\hline Communication skills & $\begin{array}{c}5 \\
(1-8)\end{array}$ & $\begin{array}{c}6 \\
(5.6 \%)\end{array}$ & $\begin{array}{c}7 \\
(6.5 \%)\end{array}$ \\
\hline Organisational skills & $\begin{array}{c}6 \\
(1-8)\end{array}$ & $\begin{array}{c}10 \\
(9.3 \%)\end{array}$ & $\begin{array}{c}7 \\
(6.5 \%)\end{array}$ \\
\hline $\begin{array}{l}\text { Ability to implement and } \\
\text { retain feedback }\end{array}$ & $\begin{array}{c}7 \\
(1-8)\end{array}$ & $\begin{array}{c}2 \\
(1.9 \%)\end{array}$ & $\begin{array}{c}44 \\
(41.1 \%)\end{array}$ \\
\hline
\end{tabular}

*Factors ranked I = most influential, 8 = least influential

mixed and acute care settings. Of all the participants, 96 (78.7\%) participants reported students always or most of the time met the expected number of patients per day productivity target. Whilst $83(70.9 \%)$ participants reported students always or most of the time met the billable units per day productivity target. Furthermore, 90 participants $(81.1 \%)$ responded that when a student did not manage a full entry level caseload, they would consider capability when rating the student's performance on the CPI. The CIs across all settings considered capability to manage a full caseload when scoring the CPI $\left(\chi^{2}=10.856, d f=5\right.$, $P=0.054)$.

\section{Caseload capability}

Respondents identified patient complexity and clinical reasoning accuracy to be most influential. Clinical reasoning speed, ability to multitask, communication skills, documentation efficiency, and organisational skills were moderately influential. The ability to retain and implement feedback was deemed least influential. Table 5 displays each factor's median rank and the number and percentage of respondents who ranked each factor as most or least influential.

\section{Discussion}

In this study, CIs reported differing methods in how their employer measured productivity. Half of the respondents reported productivity was assessed using both number of patients and billable units per day, whilst the remaining respondents stated that only utilised number of patients or billable units per day were assessed. This inconsistent approach to calculating productivity is reflected in the literature with productivity being reported as billable units, ${ }^{19,20}$ number of treatments per hour, ${ }^{20}$ day, ${ }^{3}$ or week, ${ }^{21}$ patient evaluations per hour, ${ }^{20}$ percentage of billable time per day, ${ }^{3}$ and patient visits per week. ${ }^{21}$ With the CPI's dependence on clinical sites' new graduate caseload expectations and employers utilising a variety of metrics to assess productivity, it may be challenging to assess student caseload consistently.

Most employers in this study did not have defined differing expectations for students, new graduates, or seasoned physical therapy clinicians despite the CPI asking CIs to report their employer's new graduate caseload expectations and percentage of that caseload the student had the capability to manage. For the $32 \%$ of respondents, who reported established and differing employer productivity expectations, new graduates and students were most frequently held to the same expectation with a separate expectation for seasoned clinicians. Maintaining the same expectations for students and new graduates aligns with the expectation that students should demonstrate readiness to enter clinical practice at the time of programme completion. ${ }^{1}$ It is unknown if the reported $68 \%$ of employers in this study without a defined new graduate and/ or student expectation, maintain the same productivity expectations for all clinicians or had a differing but undefined standard based on clinicians' level of clinical experience. There is conflicting evidence on the influence of years of experience on productivity with one study finding a negative correlation between years of clinician experience and productivity, ${ }^{22}$ whilst another cited a loss in productivity with the loss of experienced staff. ${ }^{23}$

Entry level caseload expectations reported by CIs for student physical therapists varied across settings in the number of patients and number of billable units expected. For example, in OP orthopaedics, CIs reported a median expectation of 9 patient visits and 25 billable units per 8-hour day. However, in inpatient rehabilitation units CIs reported an expectation of 4.5 patient visits and 21 billable units. The CI's caseload expectations in this study aligned with the APTA 2016-17 Physical Therapy Productivity Summary Report with a progressively increasing number of patient visits per day expected in inpatient rehab, acute care, and OP practice. ${ }^{21}$ These varying expectations align with the differing needs and demands of each clinical setting.

Within each clinical setting, this study found a range in reported CI's caseload expectations. This range may lead to situations in which a student could meet caseload expectations at one facility, but not another despite the facilities being consistent in practice setting. For example, in OP orthopaedics, CIs reported a range of expectations of 5-16 patients per day for students. Differing expectations place students at risk for failure that could lead to 
significant educational, emotional, and financial consequences. Conversely, a student whose expected caseload is at the lower end of the range may not experience the challenge of a full caseload, leaving the student potentially ill-prepared for realistic clinical practice because of limited mastery of time management skills with fewer patient visits per day. The range in CI expectations within a setting may cause inequality in the assessment of student performance and learning opportunities.

The accurate rating of student caseload performance is further complicated by the ability for a CI to consider the student's capability of maintaining $100 \%$ of a full-time physical therapist caseload. ${ }^{5}$ The CPI instructions offers no additional guidance on what Cl's should consider when determining a student's capability. In this study, $81 \%$ of CIs reported considering a student's capability of managing a full entry level caseload if the student was not meeting the facilities' productivity expectations. This flexibility is valuable when external circumstances limit the ability of the student to demonstrate entry level caseload, but also creates room for subjectivity. Caseload interpretation within the CPI has been described as "vague"7 and CI's ratings of student performance can be influenced by many factors ${ }^{8-12}$ including a student 'being open-minded', possessing effective communication and interpersonal skills, and CI's 'gut feelings. ${ }^{10}$

Respondents reported patient complexity and accuracy of clinical reasoning as the two most influential factors when determining student caseload capability. This finding is consistent with research by Jette et al., ${ }^{11}$ who determined clinical reasoning making is the primary attribute that CIs use to determine ELP. Within the CPI, patient complexity is a performance element and clinical reasoning is a performance criterion. ${ }^{5}$ The duplication of patient complexity and clinical reasoning as explicit components of the CPI and in the determination of student caseload capability may speak to the perceived importance CIs in this study place on these factors in successful daily clinical practice.

Clinical reasoning speed, ability to multitask, documentation efficiency, and communication skills were reported as moderately important factors in CI's determination of capability. These factors relate to student physical therapists' ability to manage time efficiently. Johnson et al. ${ }^{3}$ found it can be challenging for novice physical therapist clinicians to manage their workday to meet productivity standards and difficulty communicating has caused CIs to question students' ability to demonstrate ELP. ${ }^{10}$ These findings support respondents consideration of efficiency factors as moderately important.

The ability to implement and retain feedback was reported as least influential in determining student caseload capability. Whilst feedback is impactful for student performance outcomes during clinical experiences, ${ }^{16}$ the ability to provide ongoing evaluation and to implement changes based on the patient's presentation and feedback has been reported as a critical entry level skill. ${ }^{10}$

The results of this study suggest a possible range of CI's expectations for student caseload performance within practice settings and reinforces the value placed on clinical reasoning and patient complexity in CI's determination of student caseload capability. However, limitations to this study include its small sample size with limited subgroups, respondents being limited to a single state, and overall low response rate which hinders the generalisability of this study beyond the sample examined. Whilst this survey was reviewed by experts prior to distribution, reliability testing was not performed which may influence the reliability of findings. As a result of the small response rate in some settings, some practice areas were collapsed to create a larger sample size which may minimise or eliminate the influence of medical acuity and diagnosis and decrease the power of the statistical analysis making it difficult to identify statistically significant differences. Future studies should include a larger and more diverse sample, creating a more accurate assessment of student caseload expectations and factors influencing the determination of student physical therapist capability.

\section{Conclusion}

In this study, multiple methods of assessing clinician productivity were reported. Most respondents indicated their site lacked defined and differing expectations for new graduate clinicians. The CIs consistently reported considering student capability of carrying a full caseload when making determinations of student performance on the CPI and were most influenced by patient complexity and clinical reasoning accuracy. The CI's expectations for students' full caseload aligned with trends in national data across practice settings. A range of $\mathrm{CI}$ expectations for the number of patient visits and billable units expected per day were identified within settings. The range in CI expectations within settings may contribute to inconsistent assessment of student performance on the CPI.

\section{Conflict of interest and funding}

The authors have no conflicts of interest. This work was funded by the University of Michigan-Flint, Office of the Provost.

\section{Ethics statement}

This study was approved by the University of Michigan Flint Institutional Review Board, HUM00134148.

\section{References}

1. American Council of Academic Physical Therapy. Clinical Education Summit: Summit report and recommendations. Available from: https://acapt.org/docs/default-source/reports/post-summitreport-sept-2015.pdf?sfvrsn=7e49b3d8_2 [cited 28 October 2020]. 
2. American Occupational Therapy Association. Consensus statement on clinical judgement in health care settings. Available from: https://www.aota.org/-/media/Corporate/Files/Practice/ Ethics/APTA-AOTA-ASHA-Concensus-Statement.pdf [cited 28 June 2021].

3. Johnson D, Snedeker K, Swoboda M, et al. Increasing therapist productivity: Using lean principles in the rehabilitation Department of an Academic Medical Center. J Healthc Qual 2017; 39: 270-277. doi: 10.1097/JHQ.0000000000000013

4. Tammany J, O'Connell J, Allen B, Brismée J. Are productivity goals in rehabilitation practice associated with unethical behaviors? Arch Rehabil Res Clin Trans 2019; 1(1-2): 100002. doi: 10.1016/j.arrct.2019.100002

5. Awarski G, Ellis B. Updates on clinical performance instrument. Presented at: Clinical Education Special Interest Group Meeting at American Physical Therapy Association Combined Sections Meeting, San Antonio, TX, 18 February 2017.

6. Physical Therapist Clinical Performance Instrument. Alexandria, VA: American Physical Therapy Association; 2006. Available from: https://apta.org/PTCPI/ [cited 27 June 2021].

7. Roach KE, Frost JS, Francis NJ, et al. Validation of the revised physical therapist clinical performance instrument (PT CPI): Version 2006. Phys Ther 2012; 92(3): 416-28. doi: 10.2522/physical therapistj.20110129

8. Sass K, Frank L, Thiele A, et al. Physical therapy clinical educators' perspectives on students achieving entry-level clinical performance. J Phys Ther Educ 2011; 25(3): 46-52. doi: 10.1097/00001416-201107000-00008

9. Alexander HA. Physiotherapy student clinical education: the influence of subjective judgments in observational assessment. Assess Eval High Ed 1996; 21(4): 357-66. doi: 10.1080/0260293960210406

10. Cross V, Hicks C. What do clinical educators look for in physiotherapy students? Physiotherapy 1997; 83(5): 249-60. doi: 10.1016/S0031-9406(05)66217-7

11. Jette DU, Bertoni A, Coots R, et al. Clinical instructors' perceptions of behaviors that comprise entry-level clinical performance in physical therapist students: a qualitative study Phys Ther 2007; 87(7): 833-43. doi: 10.2522/ptj.20070003

12. Cross V. Begging to differ? Clinicians' and academics' views on desirable attributes for physiotherapy students on clinical placement. Assess Eval High Educ 1998; 23(3): 295-311. doi: 10.1080/0260293980230306

13. Durand RP, Levine JH, Lichtenstein LS, et al. Teachers' perceptions concerning the relative values of personal and clinical characteristics and their influence on the assignment of students' clinical grades. Med Educ 1988; 22(4): 335-41. doi: 10.1111/j.1365-2923.1988.tb00762.x
14. Tsuda H, Low S, Vlad G. A description of comments written by clinical instructors on the clinical performance instrument. J Phys Ther Educ 2007; 21(1): 56-62. doi: 10.1097/00001416-200701000-00008

15. Wetherbee E, Dupre A, Feinn RS, Roush S. Relationship between narrative comments and ratings for entry-level performance on the Clinical Performance Instrument: A call to rethink the clinical performance instrument. J Phys Ther Educ 2018; 32(4): 333-43. doi: 10.1097/JTE.0000000000000060

16. English ML, Wurth RO, Ponsler M, Milam A. Use of the physical therapist clinical performance instrument as a grading tool as reported by academic coordinators of clinical education. J Phys Ther Educ 2004; 18(1): 87-92. doi: 10.1097/00001416-200401000-00012

17. Hayes KW, Huber G, Rogers J, Sanders B. Behaviors that cause clinical instructors to question the clinical competence of physical therapist students. Phys Ther 1999; 79(7): 653-67. doi: 10.1093/physical therapistj/79.7.653

18. IBM Corp. Released 2019. IBM SPSS Statistics for Windows, Version 26.0. Armonk, NY: IBM Corp; 2019.

19. Pabian PS, Dyson J, Levine C. Physical therapist productivity using a collaborative clinical education model within an acute care setting: a longitudinal study. J Phys Ther Educ 2017; 31(2): 11-17. doi: 10.1097/00001416-201731020-00003

20. Apke TL, Whalen M, Buford J. Effects of student physical therapists on clinical instructor productivity across settings in an academic medical center. Phys Ther 2019; 100(2): 209-15. doi: 10.1093/physical therapistj/pzz148

21. American Physical Therapy Association. 2016-2017 physical therapist productivity summary report. Available from: https://www. apta.org/contentassets/f2bf9384d8cc4b9580e2e8e7907dbc50/ practiceprofile.pdf [cited 27 June 2021].

22. Ozelie R, Janow J, Kreutz C, et al. Supervision of occupational therapy level II fieldwork students: Impact on and predictors of clinician productivity. Am J Occup Ther. 2015; 69(1): 6901260010. doi: 10.5014/ajot.2015.013532

23. Bartel A, Beaulieu N, Phibbs C, Stone P. Human capital and productivity in a team environment: Evidence from the healthcare sector. Am Econ J Appl Econ. 2014; 6(2): 231-59. doi: 10.1257/app.6.2.231

\section{*Erica Sherman}

2157 William SWhite Building

303 East Kearsley St, Flint, MI 48502, USA 
Appendix I.

\section{Caseload Survey}

Consent to Participate in a Research Study-Online Survey

By clicking on 'Yes, I agree to participate', you are consenting to participate in this research survey. If you do not wish to participate, select 'No, I do not wish to participate' to exit the survey.

- Yes, I agree to participate.

- No, I would prefer not to participate at this time.

1. Please indicate your age.

2. Please indicate your gender.

- Male

- Female

- Other

3. How many years have you been a licensed physical therapist?

4. Is the facility at which you are currently employed in the state of Michigan?

- Yes

- No

5. How many years have you been employed at your current facility as a physical therapist?

6. Which of the following would you describe as your primary patient caseload?

- Outpatient Orthopaedics (1)

- Outpatient Neuromuscular (2)

- Outpatient with mixed caseload (ortho, neuro) (3)

- Outpatient Paediatrics- Clinic based (4)

- Outpatient Paediatrics- School based (5)

- Outpatient Wound Care or Lymphedema (6)

- Outpatient Women's/Men's Health (Pelvic Floor) (7)

- Outpatient Industrial setting (8)

- Inpatient Acute Care - Non critical care (9)

- Inpatient Acute Care - Critical care (10)

- Inpatient Rehabilitation Unit (11)

- Skilled Nursing Facility (12)

- Home Health Care (13)

- Other - Please specify (14)

7. How many licensed physical therapists are employed at your facility?

8. On average, how many students per year complete terminal internships/clinical experiences (defined as full time clinical experiences at the end of the DPT curriculum) in your facility?
9. Do you act as a clinical instructor in your current role?

- Yes

- No

10. How many years have you been a clinical instructor?

11. How many full time (defined as 40 hours/week for 4 or more weeks) students have you acted as a Clinical Instructor for in the last 2 years?

12. Are you an APTA Credentialed Clinical Instructor? Check all that apply.

- Yes, I have completed the APTA Basic Clinical Instructor Training. Please indicate year completed.

- Yes, I have complete the APTA Advanced Clinical Instructor Training. Please indicate year completed.

- No.

13. Have you completed the APTA PT Clinical Performance Instrument (CPI) Online Training and Assessment Program?

- Yes, please specify year completed:

- No

14. Does your facility define your productivity target by number of patients seen, billable units, or a combination of both?

- Number of Patient seen per day

- Number of Billable units provided per day

- Both factors are used to determine productivity expectations

15. How many patients do you need to see during an 8 hour shift to reach your target productivity as defined by your facility?

16. How often do you reach this target number of patients for productivity?

- Always

- Most of the time

- About half the time

- Sometimes

- Never

17. How many billable units are you expected to produce during an 8 hour shift to reach your target productivity as defined by your facility? 
18. How often do you reach this target of billable units for productivity?

- Always

- Most of the time

- About half the time

- Sometimes

- Never

19. Does your facility have defined but differing expectations for students, new graduate therapists, and seasoned clinicians related to productivity?

- Yes

- No

20. Which of the following best describes your facility's expectations?

- No difference for new grads or seasoned clinicians, but lower expectations for students.

- Students and new graduates have lower expectations.

- No difference for any clinician regardless of experience/ status.

21. To meet the entry level expectation of carrying a full caseload, how many billable units per day do you expect a student at the end of a full time terminal clinical experience to bill for in your clinical setting?

22. To meet the entry level expectation of carrying a full caseload, how many patients do you expect a student to carry at the end of a full time terminal clinical experience in your clinical setting?

23. If a student does not meet your facility's criteria for full entry level caseload, do you consider the students capability of doing so in determining their performance rating on the CPI?

- Yes.

- No.

24. Which of the following factors influence your determination of a student's caseload capability? Please rank 1-8 with the most influential being 1 , least influential being 8 .

Efficiency of documentation (1)

Ability to multitask or handle multiple tasks simultaneously (2)

Speed of clinical reasoning (3)

Accuracy of clinical reasoning (4)

Communication skills (5)

Organisation skills (6)

Ability to implement and retain feedback (7)

Patient complexity (8)

25. Please provide with us any additional information about how you determine if a student is capable of maintaining $100 \%$ of a full time physical therapists caseload in a cost effective manner: 